\title{
PROPERTIES AND MICROSTRUCTURE OF MODELED HEAT-AFFECTED ZONE OF P92 STEEL
}

\author{
Kristýna STERNADELOVÁ, Petr MOHYLA, Michael TROMBIK, Hana (KONÍČKOVÁ) KRUPOVÁ \\ VSB - Technical University of Ostrava, Ostrava, Czech Republic, EU, kristyna.sternadelova@vsb.cz \\ https://doi.org/10.37904/metal.2019.843
}

\begin{abstract}
This paper is focused on the modelling of the heat-affected zone of steel P92 during one layer TIG (141) welding. Simulation of the heat-affected zone (HAZ) was performed on the thermal cycle simulator of its own design. The test results of mechanical properties of the modelled HAZ are compared with the results obtained on real welded joints. Critical parts of ultra-supercritical (USC) boilers are welded joints. This significantly affects the operational reliability and service life of components in USC blocks. Therefore, this work is focused just on the research of the properties of HAZ of P92 steel. The thermal cycle simulator allows transferring the properties of very small HAZ to the sufficiently large sample where the tests of the mechanical properties can be performed. Satisfactory accordance was found when comparing the microstructure and mechanical properties of real welds and simulated samples.
\end{abstract}

Keywords: Heat Affected Zone, Steel P92, Thermal Cycle Simulator, Microstructure

\section{INTRODUCTION}

The efficiency of power plants is also affected by the amount of input fuel consumed, the amount of electricity produced and the amount of $\mathrm{CO} 2$ emitted into the air. P92 steel is designed for supercritical superheated steam parameters, which increase boiler efficiency and thus reduce CO2 emissions. Steel P92 is currently considered as one of the best modified chromium steel grades in terms of creep resistant strength (CRS). Critical parts of ultra-supercritical (USC) boilers are welded joints. Especially the HAZ appears to be the weakest point in terms of microstructure degradation [1].

Thermo-mechanical simulators that can model forming, welding and heat treatment technologies have been developed to maximize production quality with the lowest cost of production. The thermo-mechanical simulator is based on the principle of ohmic heating with the passage of electric current through the sample. A simulator that can accurately define and also measure the cooling of a temperature cycle can be fully utilized for welding research and development. It is possible to achieve very good agreement between laboratory simulations and results from the real manufacturing process by using this methodology due to the precise control method and good experiment repeatability [2]. Figure 1 shows a sample during the simulation of the welding thermal cycle on the thermal cycle simulator.

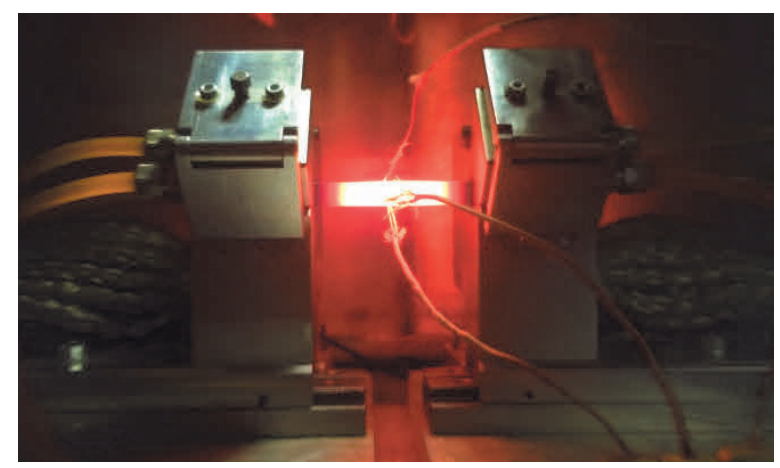

Figure 1 The simulation of the welding thermal cycle on the thermal cycle simulator 


\section{EXPERIMENT}

The samples were subjected to a thermal cycles on a thermal cycle simulator which was developed as part of the project (FR-TI3/206) of the Ministry of Industry and Trade of the Czech Republic.

Base material was heat resistant modified chromium steel P92. Chemical composition was measured using GDOES method, which is suitable for the measurement of heat resistant steels. Moreover, it is useful for measuring of surface layers [3,4]. Chemical composition of base material is indicated in Table 1.

Table 1 Chemical composition of base material - Steel P92, wt.\%

\begin{tabular}{|c|c|c|c|c|c|c|c|c|c|c|c|}
\hline $\mathrm{C}$ & $\mathrm{Mn}$ & $\mathrm{Si}$ & $\mathrm{Cr}$ & $\mathrm{W}$ & $\mathrm{Mo}$ & $\mathrm{V}$ & $\mathrm{Nb}$ & $\mathrm{N}$ & $\mathrm{B}$ & $\mathrm{P}$ & $\mathrm{S}$ \\
\hline 0.109 & 0.44 & 0.30 & 8.86 & 1.69 & 0.404 & 0.191 & 0.049 & 0.048 & 0.0033 & 0.016 & 0.0026 \\
\hline
\end{tabular}

Data were entered into the thermal cycle simulator control software for the given area of the HAZ according to the measured thermal cycle. The measured thermal cycle corresponded to the normalization band for singlelayer welding of P92 steel by 141 - TIG method. The sample was heated to a maximum temperature of $1060^{\circ} \mathrm{C}$ on a thermal cycle simulator and then cooled according to the measured thermal cycle, see Figure 2. The results of the simulation were used for modelling of the normalization band's thermal cycle of the HAZ on the test samples. Thereafter, the samples were exposed to heat treatment at $760{ }^{\circ} \mathrm{C}$ with different dwell times $(1$ to 6 hours). For comparison, one sample after thermal cycle simulation was left without heat treatment for mechanical tests.

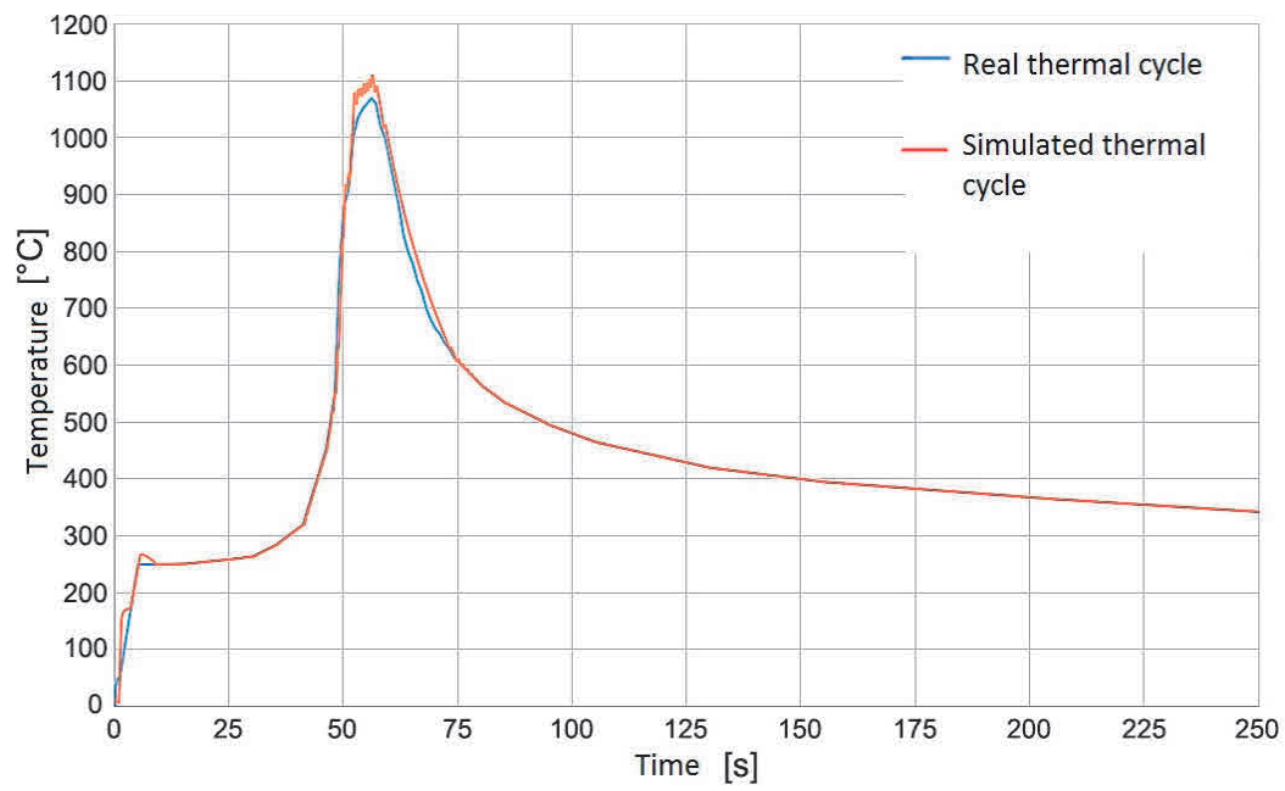

Figure 2 Comparison of measured and simulated thermal cycles.

\subsection{Impact test}

The impact test was carried out in accordance with ČSN EN ISO 148-1 [5]. The following Figure 3 shows the resulting impact work values depending on the heat treatment mode and also compares the results from the heat affected zone (HAZ) of real welds.

From the evaluation of impact test results, the trend of the individual curves is the same. Both curves rise from the outset with increasing heat treatment time up to four hours, where the impact work is maximal. During heat treatment with a dwell time of 6 hours, the values are already decreasing. 


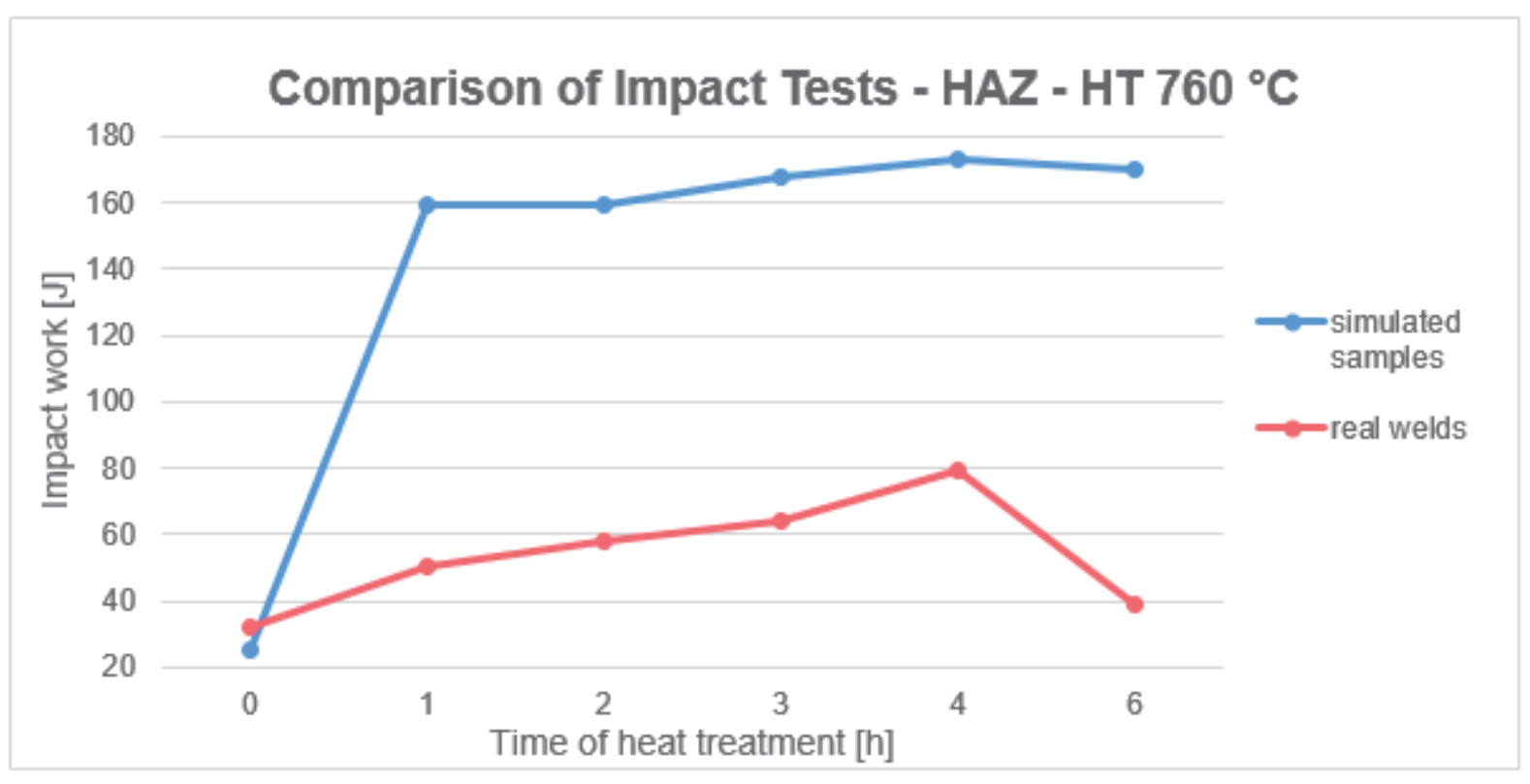

Figure 3 Comparison of results with previous experiments

\subsection{Hardness test}

Hardness tests were performed using the Vickers method with a load of $10 \mathrm{~kg}$. The measurements were taken in the center of the simulated HAZ on each sample. The average hardness values were always calculated from five measurements. All samples were treated under the same conditions like samples for impact tests.

The test results were incorporated into the Figure 4. For comparison, the results of the currently simulated samples are presented together with the results of the real welds (measured in HAZ).

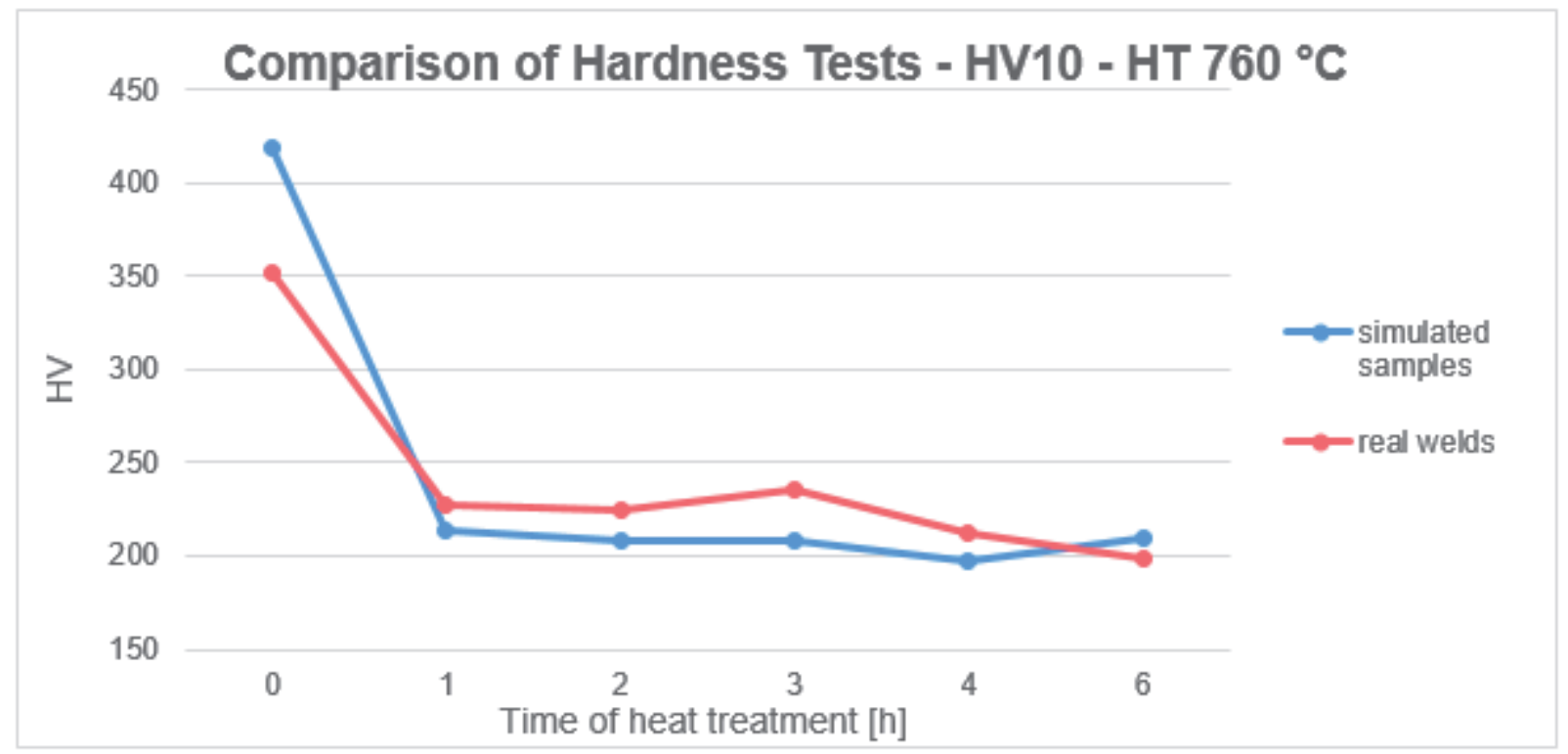

Figure 4 Comparison of hardness test's results

Figure 4 shows the same trend of curves for all measurements. The highest hardness of the HAZ is for the sample without heat treatment (up to $450 \mathrm{HV}$ ). The hardness of the heat treated samples decreases from about $230 \mathrm{HV}$ to $200 \mathrm{HV}$. The lowest hardness values were found at a temperature time dwell of four hours for the simulated samples and six hours for the real welds. 


\subsection{Microstructure}

Microscopic analysis was performed on selected samples using an optical microscope. In order to compare the microstructure of the heat treated and unheated base metal and the HAZ (see Figures 5, 6), the microstructure control was always performed in the simulated HAZ and at the edge of the samples.
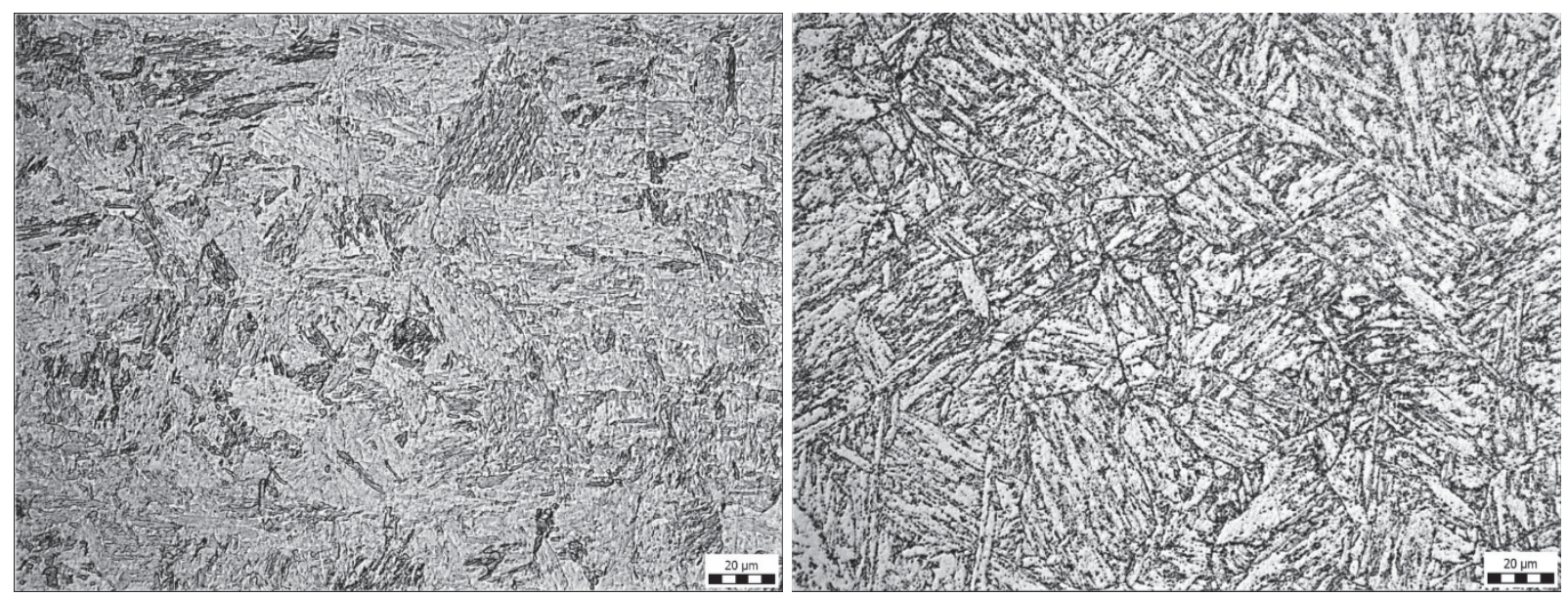

Figure 5 Microstructure of a sample without heat treatment. Left: HAZ, right: base metal
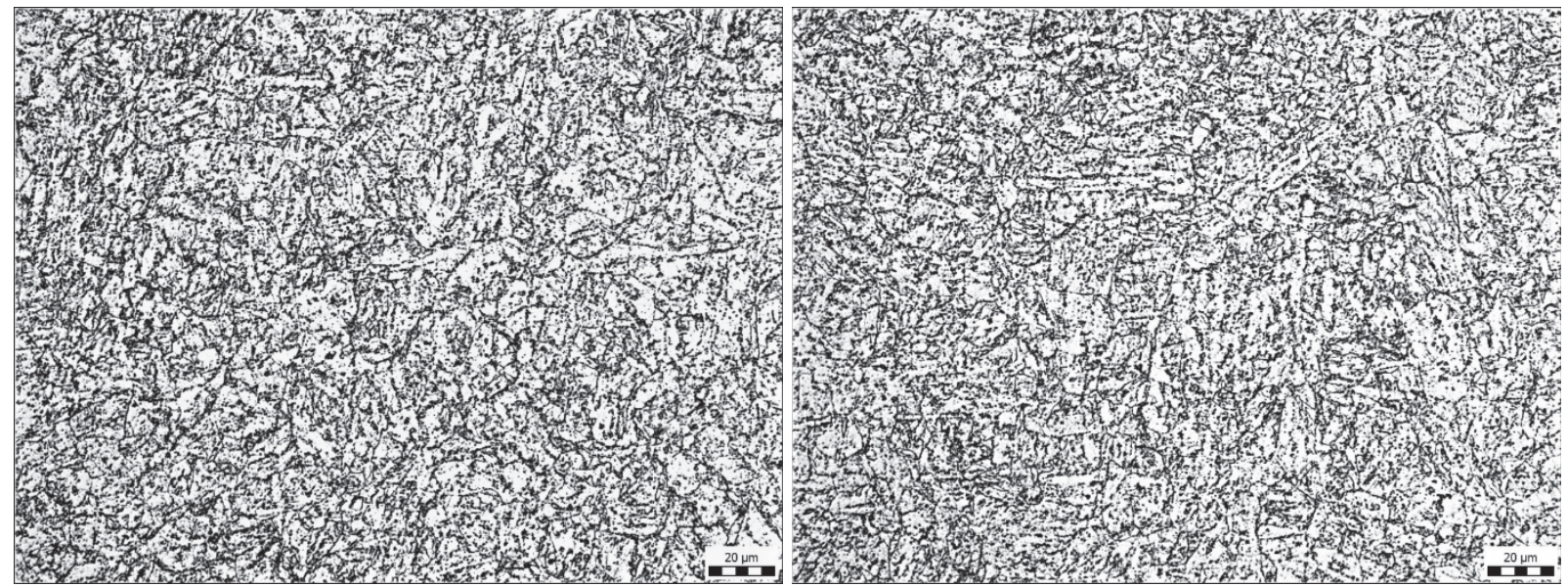

Figure 6 Microstructure of a heat treated sample, HAZ. Left: $760{ }^{\circ} \mathrm{C} / 2 \mathrm{~h}$, right: $760{ }^{\circ} \mathrm{C} / 6 \mathrm{~h}$

The microstructure of the sample in the simulated HAZ without subsequent heat treatment is purely martensitic. In all other cases, both in the HAZ and in the base metal, it is tempered martensite with carbides.

Compared to the base material, the microstructure of the HAZ is more fine-grained. With increasing annealing time, a more pronounced coagulation of carbides is observed.

\section{CONCLUSION}

This work includes comparison of mechanical properties of samples with simulated thermal cycles with properties of real welded joints of steel P92. HAZ simulations were performed on P92 steel samples, which were then heat treated at $760^{\circ} \mathrm{C}$ with different dwell times for 1 to 6 hours. Impact test, hardness test and microstructure analysis were performed on the samples thus prepared.

Samples without heat treatment after thermal cycle simulation are insufficient due to low impact work and high hardness. The hardness of the heat treated samples is less than $230 \mathrm{HV}$. Extending the heat treatment time 
from one to four hours has a relatively small effect on hardness values as opposed to the impact work, which is higher after heat treatment.

The microstructure analysis point to structural similarity in the individual samples observed. Tempered martensite and carbides were observed in both the HAZ and the base metal. The microstructure control shows that the longer the annealing time, the greater the coagulation of carbides.

Using a thermal cycle simulator provides a highly accurate and repeatable result. The results show that the use of a thermal cycle simulator to investigate the properties of a HAZ seems justified.

\section{ACKNOWLEDGEMENTS}

This work was supported by the Ministry of Industry and Trade of the Czech Republic as part of the FR-TI3 / 206 project.

\section{REFERENCES}

[1] KRAUS, M., MAREŠ, V. and BYSTRIANSKY, J. Evaluation of Materials Degradation Extent after their Long Term Exposition in Power Plants Equipments. Materials Science Forum. 2014. vol. 782, pp. 325-330.

[2] KÁŇA, J., VOREL, I. and RONEŠOVÁ, A. Simulator of thermomechanical treatment of metals. In 26 th DAAAM: $26^{\text {th }}$ Symposium on Intelligent Manufactory and Automatization. Zadar: Katalinic, 2018, pp. 0513-0518.

[3] MOHYLA. Utilization of GDOES for the study of friction layers formed on the surface of brake discs during the friction process. Chemical Papers. 2017. vol. 71, no. 8, pp. 1507-1514.

[4] VONTOROVÁ, J. and P. VÁŇOVÁ. Determination of carburized layer thickness by GDOES method AIMS. Materials Science. 2018. vol. 5, no. 1, pp. 34-43.

[5] ČSN ISO 148-1. Kovové materiály - Zkouška rázem v ohybu metodou Charpy - Část 1: Zkušební metoda. $2^{\text {nd }}$ ed. Praha: Český normalizační institut, 2009. 